\title{
Use of Flavored Drinking Water in Calves and Lactating Dairy Cattle
}

\author{
L. C. Thomas, T. C. Wright, A. Formusiak, J. P. Cant, and V. R. Osborne ${ }^{1}$ \\ Department of Animal and Poultry Science, University of Guelph, Guelph, Ontario, Canada N1G 2W1
}

\begin{abstract}
Experiments were conducted to investigate the use of added flavor in drinking water of Holstein calves and lactating dairy cattle to determine effects on dry feed intake. Nine calves were used in a replicated $3 \times$ 3 Latin square design, and water offered was unflavored or flavored with orange or vanilla. All calves were offered commercial starter. Feed intake of the dry starter was increased in calves offered the orange flavor treatment compared with the control or the vanilla treatment. The increased dry feed intake agreed with the significant increase in weight gain measured in calves on the orange treatment. Further experiments were performed with 4 second-lactation cows using the addition of another orange flavor to the water compared with unflavored water under conditions of free access or time-restricted water access. No significant changes were found for dry matter intake, water consumption, or milk yield. These findings demonstrate an important finding that flavoring agents need not be added only to the starter feed for calves, but flavor can stimulate dry feed intake and BW gain when used in drinking water.
\end{abstract}

Key words: orange, flavor, water, dairy calf

\section{INTRODUCTION}

The sense of taste in dairy cattle is well developed (Albright, 1993), although Baumont (1996) noted that there is no accounting for sensory response in prediction systems for feed intake. The areas of interest for researchers investigating feed intake have traditionally been the nutrient content of feeds (NRC, 2001), postingestive feedback (Provenza, 1995), and sensory properties, including the hedonic value of a feed to the animal (Baumont, 1996). The primary use of added flavor has been its inclusion with dry feed, but flavors incorporated as additives to feed have the potential to mix with preexisting flavors present in the other ingredients and produce secondary flavors.

Received February 6, 2007.

Accepted April 9, 2007.

${ }^{1}$ Corresponding author: vosborne@uoguelph.ca
Nombekela et al. (1994) reported a short-term preference for a diet that included $1.5 \%$ sucrose in early lactation dairy cows, but Nombekela and Murphy (1995) reported no increase in feed intake during the 12 wk after calving by including $1.5 \%$ sucrose compared with a control diet. Murphy et al. (1997) also did not find an increase in feed intake between a control or a sweetened TMR.

The inclusion of flavor with water has been used previously in ruminants to provide information on the primary tastes (sweet, salty, bitter, and sour; Goatcher and Church, 1970a,b). Flavor has been used with neonatal calves by including it in milk replacer or calf starter, which increased DMI (Morrill and Dayton, 1978; Thomsen and Rindsig, 1980). Nolte and Provenza (1991) included flavor in the milk offered to lambs, which was paired with, or novel to, flavor available in their dry feed. Dry food intake was increased in rats offered water containing $0.2 \%$ saccharin, but not when $1 \%$ almond extract was included in water (Tordoff and Friedman, 1989). An advantage of including flavor in drinking water is the ability for a direct determination of the effect of flavor.

Baumont (1996) concluded that several questions related to palatability and behavior in ruminants remain unanswered, including whether or not it was possible to enhance long-term feed intake by increasing the hedonic perception of the feed without affecting its nutritive value. There is no information on the kinetics of flavor release from drinking flavored water in ruminants. Normand et al. (2004) modeled flavor release during drinking in humans and reported that there was considerable variation between subjects, but that significant amounts of flavor and aroma remain after drinking has finished because of the residual liquid remaining in the throat after swallowing. To our knowledge, the relationship between flavoring of water and dry feed intake has not been investigated in the dairy animal, and our hypothesis was that a palatable flavor in water would increase dry food intake.

The objectives of this study were to investigate the effect of flavored water on feed and water intake and performance of Holstein calves and lactating cows. A test of water flavor preference and the use of restricted 
temporal access to water were also examined in lactating cows.

\section{MATERIALS AND METHODS}

The University of Guelph Animal Care Committee approved all experimental procedures and ensured the trials were conducted in accordance with the Canadian Council on Animal Care (1993) guidelines.

\section{Calf Study}

Diets, Animals, and Housing. Holstein heifer calves were kept in individual pens $(1.5 \times 1.2 \mathrm{~m})$ in the calf unit at the Elora Dairy Research Station (University of Guelph). Continuous lighting was provided to allow for 24-h video recording of the animals. The pens had concrete floors that were covered with shavings and were equipped with two 5-L buckets, one containing feed and the other containing water with the corresponding treatment. Water and calf starter (Rumax 20\% Calf Starter, Floradale Feedmill Limited, Floradale, Ontario, Canada) were provided for ad libitum access. Intakes of water and starter were recorded daily. Fresh water was provided twice daily at morning and evening feeding. Whole milk (2 L) was offered by bucket feeding twice daily at 0730 and $1630 \mathrm{~h}$ by placing it in the bucket holder that normally contained the water. Calves were weighed at the start of the experiment and after every treatment. Fecal scores were recorded daily using a 3 -point scale where $1=$ normal feces, $2=$ thin feces, and $3=$ scours. Nine calves were used in 3 replicates of a $3 \times 3$ Latin square design with 7-d periods. At the start of the experiment, the calves were 21 to $28 \mathrm{~d}$ old, weighed $58.7 \pm 5.6 \mathrm{~kg}$ (mean, SD) and they were randomly assigned to treatment. Treatments were control (unflavored) water, vanilla extract (McCormick, London, Ontario, Canada) flavored water, or orange extract (McCormick) flavored water at a $5 \%$ inclusion level in drinking water (50 $\mathrm{ml} / \mathrm{L}$ ).

Calf Behavior. Animals were videotaped continuously on 3 random days during each treatment. Drinking and feeding frequency and duration were recorded from the videotapes for each calf. Feeding behavior was defined as starting when the calf completely placed its head inside the starter bucket if subsequent lifting of the head was accompanied by a distinctive chewing action. When a calf completely removed its head from the partitions dividing the feeding and drinking areas, feeding behavior was considered to be finished. Drinking behavior was defined as the calf completely placing its head inside the water bucket and was considered to be completed when the calf com- pletely removed its head from inside the bucket. Drinking behavior also included consumption of milk.

Statistical Analysis of Calf Study. Statistical analysis was done using the mixed procedure of SAS (SAS Institute Inc., 1998). The model used was $\mathrm{y}=\mu$ $+\mathrm{S}_{\mathrm{i}}+\mathrm{P}_{\mathrm{j}}+\mathrm{C}\left(\mathrm{S}_{\mathrm{i}}\right)_{\mathrm{k}}+\beta\left(\mathrm{X}_{\mathrm{ijk}}\right)+\mathrm{T}_{1}+\mathrm{E}_{\mathrm{ijk}}$, where $\mu=$ the true mean, $\mathrm{S}=$ the effect of square ( $\mathrm{i}=1$ to 3 ), $\mathrm{P}=$ the effect of period ( $\mathrm{j}=1$ to 3 ), $\mathrm{C}=$ the effect of calf within square ( $\mathrm{k}=1$ to 3 ), $\beta=$ the covariate effect of calf weight $(\mathrm{X})$ at the start of each period, $\mathrm{T}=$ effect of treatment ( $1=$ no flavor or flavor), and $\mathrm{E}$ is the random residual error. When the F-statistic for the effect of flavor was significant (taken as $P<0.05$ ), least square means were separated by Tukey's comparison test. Total frequency and duration of feeding and drinking behavior were averaged for each animal from the $3 \mathrm{~d}$ that were randomly selected for videotape recording.

\section{Lactating Cow Study}

Cows and Water Delivery. Four second-lactation Holstein dairy cows (35 \pm 5 DIM) were housed in tiestalls and fed a TMR for ad libitum intake in 2 consecutive experiments. The same 4 cows were used in both of the present experiments, with the flavor preference study following the water restriction experiment. Cows had access to orange-flavored or unflavored water in only 1 of the 2 water bowls at their stall, according to treatment. Water consumption from the bowls (Dania, DeLaval Inc., Peterborough, Ontario, Canada) was measured by positive displacement water meters (ABB Kent Metres Inc., Mississauga, Ontario, Canada) that were calibrated to have an accuracy of \pm 0.5 to $1.0 \%$. Treatment was randomly assigned to the left or right water bowl and was used for the duration of the experiment. Water intake was recorded electronically for every 15 -min period. The non-sweet flavored water was delivered by a liquid injector system (Model DI 150, Dosatron International, Clearwater, FL) at a final concentration in the water bowl of $2 \mathrm{~g} / \mathrm{L}$. The flavoring additive was an orange cream emulsion (Product \#1402, Citrus and Allied Essences, Lake Success, NY) and was included at the manufacturer's recommended human inclusion level.

Experimental Design. The first experiment was a $4 \times 4$ Latin square design with 7 -d periods and a $2 \times$ 2 factorial arrangement of treatments. The first day of each period was considered to be adaptation. A fifth week of data collection was included to improve the statistical detection of possible residual treatment effects. The treatment factors were 2 methods of water access (ad libitum or restricted) and 2 flavors of water (orange flavor or unflavored). Drinking water was provided for ad libitum access, or access to water was 
Table 1. Ingredients and chemical analysis of the TMR for lactating cows

\begin{tabular}{lc}
\hline Ingredient & \% of diet DM \\
\hline Mixed hay & 5.52 \\
Haylage & 22.38 \\
Corn silage & 33.60 \\
High moisture corn & 19.37 \\
Dairy supplement ${ }^{1}$ & 19.12 \\
Chemical composition (\% of DM) & \\
DM & 42.29 \\
CP & 17.56 \\
ADF & 20.17 \\
CaF & 33.53 \\
Calcium & 0.92 \\
Phosphorus & 0.43 \\
Potassium & 1.25 \\
Magnesium & 0.26 \\
Sodium & 0.38 \\
NE $($ Mcal/kg) & 1.56 \\
\hline
\end{tabular}

${ }^{1}$ Dairy supplement (as fed): $\mathrm{NE}_{\mathrm{L}}(\mathrm{Mcal} / \mathrm{kg})=1.35 ; \mathrm{CP}=35.31 \%$; $\mathrm{Ca}=2.34 \% ; \mathrm{P}=1.23 \% ; \mathrm{Mg}=0.71 \% ; \mathrm{S}=0.75 \% ; \mathrm{Cu}=125 \mathrm{mg} / \mathrm{kg}$; $\mathrm{Se}=1.26 \mathrm{mg} / \mathrm{kg}$; vitamin $\mathrm{A}=52.5 \mathrm{KIU} / \mathrm{kg}$; vitamin $\mathrm{D}=13.12 \mathrm{KIU} /$ $\mathrm{kg}$; vitamin $\mathrm{E}=199 \mathrm{IU} / \mathrm{kg}$.

restricted to the hours from 0600 to 0800 and also from 1500 to 1700 . Flavor was provided as no additive or $2.0 \mathrm{~g} / \mathrm{L}$ of the orange flavoring additive. Video recorders were used to monitor cow behavior for duration of time spent lying down, standing, eating, and drinking, and subsequent analysis of recorded activity for drinking and standing was done according to the criteria of Huzzey et al. (2005).

The second experiment was a 2-wk water flavor preference study. Each cow was provided with access to both the unflavored water and the orange-flavored water $(2.0 \mathrm{~g} / \mathrm{L})$ for $2 \mathrm{wk}$, utilizing the 2 water bowls available at each stall. During the first week, 2 randomly chosen cows were provided the flavored water in the left-hand water bowl and regular water in the righthand bowl. The other 2 cows were assigned opposite water treatments in their bowls. At the beginning of wk 2, the treatments for each cow were switched to the opposite water bowl in order to cancel out any potential preference for the side of stall from which the cows chose to drink.

Sample Collection and Analysis. For the lactating cow study, water intake, feed intake and milk yield data were recorded daily and milk composition was determined weekly. Samples of the TMR and orts were collected daily and pooled into weekly composite samples for chemical analysis at a commercial feed laboratory (Agri-Food Laboratories, Guelph, Ontario, Canada). Diet ingredients and chemical composition are presented in Table 1. Orts and TMR samples were also placed in an oven at $60^{\circ} \mathrm{C}$ for $48 \mathrm{~h}$ to determine DM. Weekly water samples were taken from the flavored and the unflavored treatments and analyzed (Agri-
Table 2. Composition of unflavored and flavored water

\begin{tabular}{|c|c|c|c|c|}
\hline \multirow[b]{2}{*}{ Variable } & \multicolumn{2}{|c|}{$\begin{array}{l}\text { Unflavored } \\
\text { water }\end{array}$} & \multicolumn{2}{|c|}{$\begin{array}{c}\text { Flavored } \\
\text { water }\end{array}$} \\
\hline & Mean & SD & Mean & SD \\
\hline $\mathrm{pH}$ & 7.53 & 0.05 & 6.93 & 0.47 \\
\hline Total salts $(\mathrm{mmho} / \mathrm{cm})^{1}$ & 0.53 & 0.01 & 0.58 & 0.04 \\
\hline Total dissolved solids (ppm) & 339.2 & 6.4 & 373.3 & 31.57 \\
\hline Nitrate nitrogen $(\mathrm{ppm})$ & 1.23 & 5.8 & $<0.05$ & \\
\hline Total hardness (ppm) & 240.6 & 10.3 & 264.5 & 40.1 \\
\hline Phosphorus (ppm) & $<0.1$ & & $<0.1$ & \\
\hline Potassium (ppm) & 0.487 & & 10.310 & 6.6 \\
\hline Calcium (ppm) & 54.2 & 4.5 & 63.2 & 13.0 \\
\hline Magnesium (ppm) & 25.56 & 1.23 & 25.82 & 1.73 \\
\hline Bicarbonate (ppm) & 215.0 & 122.0 & 318.3 & 46.7 \\
\hline Chloride (ppm) & 6.66 & 1.15 & 12.67 & 8.08 \\
\hline Sulphates (ppm) & 36.08 & 2.87 & 162.24 & 208.9 \\
\hline Sodium (ppm) & 14.98 & 1.12 & 17.84 & 4.6 \\
\hline Zinc (ppm) & 0.03 & 0.01 & 0.27 & 0.28 \\
\hline Manganese (ppm) & 0.027 & 0.02 & 0.02 & 0.02 \\
\hline Copper (ppm) & 0.033 & 0.01 & 0.36 & 0.36 \\
\hline Iron (ppm) & $<0.01$ & & 0.037 & 0.03 \\
\hline Boron (ppm) & 0.043 & 0.01 & 0.05 & 0.00 \\
\hline Silicon (ppm) & 5.17 & 0.11 & 5.27 & 0.21 \\
\hline
\end{tabular}

${ }^{1}$ Where 1 mho = 1 siemen $(\mathrm{S})$.

Food Laboratories) for total solids, $\mathrm{pH}$, hardness, and minerals (Table 2).

Milk Collection and Analysis. Cows were milked in their stalls at approximately 0500 and $1500 \mathrm{~h}$ daily. Milk yields for each milking were recorded for the duration of the study. Milk samples collected from consecutive afternoon and morning milkings were analyzed for fat, protein, and lactose by infrared spectroscopy at the Laboratory Services Division, University of Guelph.

Statistical Analysis of Cow Study. Results from this experiment were analyzed using the mixed procedure of SAS (SAS Institute, 1998). Statistical significance was accepted at $P<0.05$. The model used for this study was: $Y_{i j k}=\mu+C_{i}+T_{j}+P_{k}+E_{i j k}$, where $\mu$ is the overall population mean, $\mathrm{C}$ is the effect of cow $(\mathrm{i}=1,2,3,4)$, $\mathrm{T}$ is the effect of treatment $(\mathrm{j}=1,2,3$, 4), $\mathrm{P}$ is the effect of period ( $\mathrm{k}=1,2,3,4,5)$, and $\mathrm{E}$ is the random residual error term. Orthogonal contrasts with single degree of freedom were used to test for main effects of flavor and water access and for an interaction between the 2 factors.

The second study that examined the preference for flavor or unflavored water was analyzed using the mixed procedure of SAS according to the following model: $\mathrm{Y}_{i s j}=\mu+C_{i}+B_{\mathrm{s}}+P_{j}+E_{i s j}$, where $\mu$ is the overall population mean, $\mathrm{C}$ is the effect of cow $(\mathrm{i}=1$, $2,3,4), \mathrm{B}$ is the placement of water bowl ( $\mathrm{s}=$ left or right), $P$ is the effect of period $(j=1,2)$, and $E$ is the random residual error term. Significant results were accepted as $P<0.05$. 
Table 3. Intakes from the calf study and measures of fecal score, average daily gain, and daily time spent feeding or drinking

\begin{tabular}{lcccc}
\hline & \multicolumn{3}{c}{ Water flavor } & \\
\cline { 2 - 4 } Measure & Control & Orange & Vanilla & SE \\
\hline Water intake (L/d) & 1.09 & 1.00 & 0.92 & 0.12 \\
Feed intake $(\mathrm{kg} / \mathrm{d})$ & $0.490^{\mathrm{a}}$ & $0.739^{\mathrm{c}}$ & $0.522^{\mathrm{b}}$ & 0.06 \\
Fecal score $^{1}$ & 1.22 & 1.19 & 1.35 & 0.09 \\
Weight gain $(\mathrm{kg} / \mathrm{d})$ & $0.82^{\mathrm{a}}$ & $1.18^{\mathrm{b}}$ & $0.74^{\mathrm{a}}$ & 0.08 \\
Time feeding $(\mathrm{min} / \mathrm{d})$ & 23.12 & 25.21 & 21.33 & 2.49 \\
Time drinking $(\mathrm{min} / \mathrm{d})$ & 15.68 & 14.34 & 12.93 & 0.84 \\
\hline
\end{tabular}

${ }^{a-c}$ Data within the same row having different superscripts are significantly different from each other $(P<0.05)$.

${ }^{1}$ Fecal score was assessed on a 3 -point scale $(1=$ normal, $2=$ thin, and $3=$ scours).

\section{RESULTS AND DISCUSSION}

\section{Calf Study}

The addition of orange or vanilla flavor did not affect $(P>0.05)$ the consumption of water compared with the control (Table 3$)$. The orange flavor in water increased $(P<0.05)$ calf starter feed intake by 249 and $217 \mathrm{~g} / \mathrm{d}$ compared with the control and vanilla flavor, respectively (Table 3 ). The vanilla flavor in water increased calf starter intake $(P<0.05)$ by $32 \mathrm{~g} / \mathrm{d}$ compared with the control.

The higher consumption of calf starter with the administration of orange flavor to the water was reflected by increased $(P<0.05)$ weight gain of 0.44 and 0.36 $\mathrm{kg} / \mathrm{d}$ compared with the control and vanilla flavors, respectively (Table 3 ). The smaller, but significant, increase in feed intake with the vanilla treatment compared with control did not result in increased rate of gain $(P>0.05$; Table 3$)$.

Providing supplemental water has been shown to be beneficial to the growing calf by maintaining water equilibrium and encouraging early calf starter intake (Kertz et al., 1984). Calves consume approximately 1 $\mathrm{L}$ of water, and sometimes more, everyday beginning at $1 \mathrm{wk}$ of age until $20 \mathrm{wk}$ of age (Kertz et al., 1984), which is similar to the amounts consumed herein (Table 3 ). At 20 wk of age, water consumption begins to accelerate, and calves consume over $2 \mathrm{~L}$ of water per day (Kertz et al., 1984).

Although a few studies have looked at applying flavors in feed to increase the acceptance and intake of certain feeds, the relationship between flavored water and feed intake has not been examined, and it may improve calf growth. Attempts to make feed more palatable are commonly done with many farm animals. For example, molasses is often used in commercial calf starters to increase palatability and feed intake in growing calves. Hereford steers were found to consume more feed when it was flavored compared with unfla- vored feed (Wallace and Riggs, 1967). Similar results were observed with dairy calves when flavors were added to calf starter. Starter intake and weight gain were greater in calves fed flavored starter than calves offered unflavored starter (Thomsen and Rindsig, 1980). Morrill and Dayton (1978) also reported that calves consumed more feed and gained more weight when offered flavor in their calf starter. Flavors can improve the initiation of feed intake and consequently increase weight gain in animals and constitute an important technique to advance feeding programs. We have shown here that the flavoring agent does not have to be included in the starter but can stimulate starter intake and BW gain when included in the drinking water.

It was not expected a priori that the orange flavor would increase calf starter intake more $(P<0.05)$ than the vanilla flavor (Table 3 ). It was predicted that both flavors would have a positive effect on feed intake given that both of these flavors are commonly used in the dairy industry. Vanilla flavor is most commonly used in milk replacers, whereas orange flavor is often used in some commercial calf starter feeds. It is possible that the orange flavor taste was complementary to the calf starter, but the vanilla was not. Similar to feed intake, weight gain also increased when calves were offered orange-flavored water, which agrees with the data for higher calf starter intake.

There was a minimal occurrence of scours by the calves on all treatments (Table 3), and there were no significant differences in fecal score between treatments. Fecal score 2 (thin feces) occurred in calves on each treatment, which is recognized as normal in the growing calf. Water treatments did not affect the incidence of scouring, and calves experienced normal fecal output throughout the majority of the experiment.

\section{Calf Behavior}

There was a trend $(P<0.10)$ for less total time spent drinking during a $24-\mathrm{h}$ period for the vanilla-flavored treatment compared with the control (Table 3). This may have been due to calves developing a negative response to vanilla-flavored water, but the motivation to consume water was strong enough that water intake still occurred. There was no significant difference $(P$ $>0.05$ ) in drinking duration time between the orange and control or orange and vanilla treatments (Table 3 ).

Time spent feeding during a 24 -h time period was not affected $(P>0.05)$ by treatment. Among the 9 calves, there was considerable variation in drinking and feeding behavior throughout a day. For some calves, drinking occurred when they stood up from a resting position to obtain some water and then return 
Table 4. Dry matter intake, water intake, and milk production data from lactating cows

\begin{tabular}{|c|c|c|c|c|c|c|c|c|}
\hline \multirow[b]{3}{*}{ Variable } & \multicolumn{4}{|c|}{ Water access } & \multirow[b]{3}{*}{$\mathrm{SE}$} & \multirow{2}{*}{\multicolumn{3}{|c|}{$P$-value }} \\
\hline & \multicolumn{2}{|c|}{ Ad libitum } & \multicolumn{2}{|c|}{ Restriction } & & & & \\
\hline & Flavor & $\begin{array}{l}\text { No } \\
\text { flavor }\end{array}$ & Flavor & $\begin{array}{l}\text { No } \\
\text { flavor }\end{array}$ & & $\begin{array}{l}\text { Water } \\
\text { access }\end{array}$ & Flavor & $\begin{array}{l}\text { Access } \\
\times \text { flavor }\end{array}$ \\
\hline DMI, kg/d & 22.7 & 23.8 & 23.6 & 22.6 & 1.1 & 0.88 & 0.97 & 0.37 \\
\hline Water, $\mathrm{kg} / \mathrm{d}$ & 89.5 & 87.0 & 88.5 & 86.8 & 2.7 & 0.81 & 0.47 & 0.88 \\
\hline Milk, kg/d & 39.4 & 39.5 & 35.8 & 38.3 & 0.4 & 0.006 & 0.01 & 0.02 \\
\hline
\end{tabular}

to the lying position. Other calves continuously switched back and forth from the feed and water bucket when standing at the feeding area.

Most research on drinking behavior in calves has focused on the drinking frequency and duration of milk consumption from buckets and teats (Hammell et al., 1988; Appleby et al., 2001). However, limited research has examined the water drinking behavior of dairy calves. Perhaps this is the case for the practical reason that calves receive most of their water requirements from milk consumption. Nevertheless, it is evident that calves consume small amounts of water throughout the day when it is available to them (Kertz et al., 1984).

\section{Lactating Cow Study}

The choice of added flavor in the lactating cow study, orange-cream emulsion, was chemically different from the orange flavor used in the calf experiment. The addition of flavor to the water of lactating cows followed the findings of the calf study, but given the differences between calves and lactating cows (including physiological and lifetime tasting experiences), it is possible that the outcome of increased dry feed consumption by the calves may have been different even with the same flavor source. There was no effect of water access treatment or flavor treatment on DMI or water intake during the experiment (Table 4). These results indicate that the non-sweet orange additive at a concentration of $2 \mathrm{~g} / \mathrm{L}$ did not motivate the cows to consume more or less water than was necessary to maintain physiological water balance. There was no effect of treatment on milk composition in this experiment (data not shown).

Cows had reduced $(P<0.05)$ milk production when they were offered restricted access to flavored water (Table 4). Identifying a specific cause for the reduction in milk production is difficult, given the absence of effects on water intake or DMI. There was an effect of previous treatment $(P<0.05)$ on milk production; however, there was no significant residual effect for the other variables measured.
When cows received restricted water access, they consumed an equal amount of water on a daily basis compared with the unrestricted cows (range from 86.8 to $89.5 \pm 2.7 \mathrm{~L} / \mathrm{d}$ for all treatments). It was expected that restricted access to water might have reduced total imbibed water intake because under conditions of ad libitum access to water, approximately $40 \%$ of daily water intake occurred within the first hour after each milking when cows were milked twice per day (Osborne et al., 2002). The later morning access to water used herein avoided the first hour postmilking. The present experiment demonstrates that water consumption patterns readily adapt to the availability of water provided and that the non-sweet orange flavor was not so unpalatable as to prevent the cows from drinking an equal amount of water on a daily basis compared with ad libitum water access. Beridot-Therond et al. (1998) reported that when only 1 beverage is provided to human subjects to drink, the flavor of the beverage has little impact on the amount of fluid consumed. This may suggest that water consumption in dairy cattle, within as yet undefined parameters of acceptability, may not necessarily be reduced in the presence of different flavors.

Water restriction is not a recommended method for management of dairy cattle, and the accepted practice is to provide for ad libitum water access. However, the development of a noninvasive water-based nutrient delivery system may also, under certain circumstances, require the delivery of nutrients or additives at concentrations in the water where higher total water intakes in a limited time period are necessary. This method of water access would eliminate the need to supply such additives continuously over the course of a day. Limitations to the temporal supply of water had no effect on total daily water intake in the present study.

The use of $\mathrm{d} 1$ from each period as an adaptation period was adopted. However, no changes to water intake were observed on the day when treatments changed. Flavor fatigue for the orange flavor was not observed in this experiment, whereby an initial preference or curiosity for a new flavor is followed by a wan- 
Table 5. Preference for water measured by consumption (L/d) with or without the non-sweet orange flavor in lactating cows

\begin{tabular}{lcrrrrr}
\hline & & & & \multicolumn{2}{c}{$P$-value } \\
\cline { 3 - 6 } Treatment & Week 1 & Week 2 & \multicolumn{1}{c}{ SE } & Period & $\begin{array}{c}\text { Bowl } \\
\text { side }\end{array}$ \\
\hline Flavor & 12.75 & 3.75 & 1.25 & 0.04 & 0.19 \\
No flavor & 77.25 & 77.50 & 14.15 & 0.99 & 0.19 \\
\hline
\end{tabular}

ing of interest or a decline in consumption (Bell, 1959). This may be related to the fact that the flavored-water treatment was the only source of drinking water provided to the cows.

The behavioral observations made from the video recordings indicated that there were no differences $(P$ $>0.05$ ) in duration of time spent lying down, standing, drinking or eating on a total basis, even though drinking activity for the restricted treatments was limited to $4 \mathrm{~h} / \mathrm{d}$. The behavioral measures were included in the $4 \times 4$ Latin square experiment to determine the ability of water access or flavor to perturb these 4 behaviors. The cows adapted to the restriction and flavor treatments as was evident by the absence of change in DMI and water intake and as demonstrated by the absence of change to the behaviors measured.

A second experiment with lactating cows was conducted to determine the flavor preference (non-sweet orange additive or no additive) for water using the same 4 cows. Data from the preference study for water intake are shown in Table 5. There was a significant decline in fluid intake over time $(9.0 \mathrm{~kg} / \mathrm{d}$ less in wk 2 than in wk 1) with the orange flavor treatment, but not for the consumption of regular water $(P>0.05)$. The side of the stall from which treatments were provided was not significant. It is important to note that the overall experimental design used in the present study may have affected the results. The use of the same cows in both experiments and the sequence (water restriction before preference study) of the experiments are important factors. The avoidance of flavored water in the preference study may have been an outcome of an association formed during the water restriction experiment.

When the orange flavor was included in drinking water at a concentration of $2 \mathrm{~g} / \mathrm{L}$ there was no difference in the amount of water consumed on a daily basis compared with unflavored water. However, given a choice, the same cows consumed plain water with a preference of 6.1:1 in the first week and 20.7:1 in the second week. Results from the first experiment with lactating cows indicated that the orange flavor additive did not provide a motivation to reduce or increase water consumption, but when given a choice their con- sumption preference was for water without the flavor additive.

\section{CONCLUSIONS}

The results of the calf study indicate that addition of the orange flavor to drinking water increased feed intake of calf starter and resulted in a higher growth rate compared with control (no flavor) or the vanillaflavored drinking water. The increase in calf starter intake resulting from the orange flavor did not affect the feeding or drinking behaviors of the calves compared with the control, nor did it result in any change in the consistency of the calves' feces. The use of orange flavor in drinking water for calves is a promising approach to improve feed intake and rate of gain in young dairy calves.

The experiments with lactating dairy cows offered the orange flavor did not reflect the increase in feed consumption observed in the calf study. Water intake was not reduced by the lactating cows offered the orange flavor. However, the preference experiment revealed a strong preference for unflavored water, which became more pronounced over time. Water restriction did not affect daily water intake compared with unrestricted water access, indicating that it may potentially be useful in the future on a limited basis to permit greater aqueous dilution of some additives without affecting drinking water intake. The addition of the orange flavor used herein has no benefit to feed intake for lactating cattle and can reduce milk production.

\section{REFERENCES}

Albright, J. L. 1993. Feeding behavior of dairy cattle. J. Dairy Sci. 76:485-498.

Appleby, M. C., D. M. Weary, and B. Chua. 2001. Performance and feeding behavior of calves on ad libitum milk from artificial teats. Appl. Anim. Behav. Sci. 74:191-201.

Baumont, R. 1996. Palatability and feeding behaviour in ruminants. Ann. Zootech. 45:385-400.

Bell, F. R. 1959. The sense of taste in the domesticated animals. Vet. Rec. 71:1071-1081.

Beridot-Therond, M. E., I. Arts, M. Fantino, and V. De La Gueronniere. 1998. Short-term effects of the flavor of drinks on ingestive behaviors in man. Appetite 31:67-81.

Canadian Council on Animal Care. 1993. Guide to the Care and Use of Experimental Animals. CCAC, Ottawa, Ontario, Canada.

Goatcher, W. D., and D. C. Church. 1970a. Taste responses in ruminants. 1. Reactions of sheep to sugars, saccharin, ethanol and salts. J. Anim. Sci. 30:777-783.

Goatcher, W. D., and D. C. Church. 1970b. Taste responses in ruminants. 2. Reactions of sheep to acids, quinine, urea and sodium hydroxide. J. Anim. Sci. 30:784-790.

Hammell, K. L., J. H. M. Metz, and P. Meking. 1988. Sucking behavior of dairy calves fed milk ad libitum by bucket and teat. Appl. Anim. Behav. Sci. 20:275-285.

Huzzey, J. M., M. A. G. von Keyserlingk, and D. M. Weary. 2005. Changes in feeding, drinking and standing behavior of dairy cows during the transition period. J. Dairy Sci. 88:2454-2461. 
Kertz, A. F., L. F. Reutzel, and J. H. Mahone. 1984. Ad libitum water intake by neonatal calves and its relationship to calf starter intake, weight gain, feces score and season. J. Dairy Prod. 67:2964-2969.

Morrill, J. L., and A. D. Dayton. 1978. Effect of feed flavor in milk and calf starter on feed consumption and growth. J. Dairy Sci. 61:229-232.

Murphy, M. R., A. W. Geijsel, E. C. Hall, and R. D. Shanks. 1997. Dietary variety via sweetening and voluntary feed intake of lactating dairy cows. J. Dairy Sci. 80:894-897.

National Research Council. 2001. Nutrient Requirements of Dairy Cattle. 7th Rev. Ed. National Academy Press. Washington, DC.

Nolte, D. L., and F. D. Provenza. 1991. Food preferences in lambs after exposure to flavors in milk. Appl. Anim. Behav. Sci. 32:381-389.

Nombekela, S. W., and M. R. Murphy. 1995. Sucrose supplementation and feed intake of dairy cows in early lactation. J. Dairy Sci. 78:880-889.

Nombekela, S. W., M. R. Murphy, H. W. Gonyou, and J. I. Marden. 1994. Dietary preferences in early lactation cows affected by primary tastes and some common feed flavors. J. Dairy Sci. 77:2393-2399.

Normand, V., S. Avison, and A. Parker. 2004. Modeling the kinetics of flavour release during drinking. Chem. Senses 29:235-245.

Osborne, V. R., R. R. Hacker, and B. W. McBride. 2002. Effect of heated drinking water on the production responses of Holstein and Jersey cows. Can. J. Anim. Sci. 82:267-273.

Provenza, F. D. 1995. Postingestive feedback as an elementary determinant of food preference and intake in ruminants source and food flavor on conditioned preference. J. Range Manage. 48:2-17.

SAS Institute Inc. 1998. SAS User's Guide. Version 7. SAS Institute Inc., Cary, NC.

Thomsen, N. K., and R. B. Rindsig. 1980. Influence of similarly flavored milk replacers and starter on calf starter consumption and growth. J. Dairy Sci. 63:1864-1888.

Tordoff, M. G., and M. I. Friedman. 1989. Drinking saccharin increases food intake and preference: 1. Comparison with other drinks. Appetite 12:1-10.

Wallace, J. D. and J. K. Riggs. 1967. Moisture, flavor, color and feed acceptability by cattle. J. Anim. Sci. 26:209. (Abstr.) 